dem Mikroskope*) scharf ein, so bemerkt man, dass bei Flachs- sowohl wie Hanffaser fast jede Faser ein überaus prächtiges Farbenspiel zeigt.

Die Jutefasern erscheinen dagegen mehr einfarbig bläulich oder gelblich, nur wenige Fasern zeigen den Leinfasern ähnliche, wenn auch weit weniger prächtige Farben. Wesentlich ist jedoch, dass die einzelnen Fasern wirklich völlig getrennt von einander sind. Liegen dieselben über oder neben einander, so entstehen an den Berührungsstellen natürlich auch bei Jute lebhaftere Färbungen. Die zur Zellwand der Bastzellen mehr oder minder senkrecht stehenden Bruchlinien derselben, sowie die diesen Bruchlinien bisweilen nicht unähnlichen Reste von anlaftendem Parenchymgewebe treten bei der Untersuchung der Fasern im polarisirten Lichte**) weit deutlicher hervor, als bei der gewöhnlichen Beleuchtung, und bieten dem Kundigen weitere Unterscheidungsmerkmale.

Ich glaubte die Ursache des prächtigen Farbenspieles von Lein- und Hanffasern im polarisirten Licht ursprünglich auf die mechanischen Einwirkungen bei der Gewinnung und Verarbeitung dieser Fasern zurückführen zu müssen, habe mich aber überzeugt, dass auch die aus Herbariumpflanzen von Linum usitatissimum and Cannabis sativa mit Hülfe des obigen Verfahrens erhaltenen Bastzellen das beschriebene Verhalten zeigten. Hiernach scheint dasselbe den betreffenden Fasern an sich eigenthümlich $\mathrm{zu}$ sein.

Wiesbaden, im December 1889.

Zur Bestimmung des Stärkemehls in Getreidearten. Von

\title{
Z. v. Milkowski.
}

Um darüber Entscheidung zu treffen, ob die von Märcker angegebene Stärkemehl-Bestimmungsmethode wirklich als allein richtige Besultate liefernde $\mathrm{zu}$ betrachten ist, habe ich mit derselben und mit der von Dr. Alex. v. Asbóth angegebenen Methode mehrere vergleichende Versuche angestellt.

Die Stärkemehlbestimmungen nach der Barytmethode von A sbóth

*) Seibert, Objectiv 3, ungefähre Vergrösserung 200.

**) Insbesondere mit Seibert's System No. 5, Vergrösserung etwa 600. 
wurden nach den Angaben des Verfassers*) mit dem Beachten ausgeführt, dass das zur Probe verwendete Getreide zunächst von Fett befreit und erst die entfettete und gut zerriebene Substanz in Quantitäten von 1 bis 2 Gramm zur Stärkemehlbestimmung verwandt wurde. Um sicher zu sein, dass mit Aether das Fett vollständig extrahirt wird, habe ich mit Schwefelkohlenstoff Gegenversuche angestellt und dabei übereinstimmende Zahlen bekommen.

$\mathrm{Zu}$ den nach der Märcker'schen Methode ausgeführten Bestimmungen wurden je $3 g$ fein gepulverter Substanz mit $50 \mathrm{cc}$ Wasser in kochendem Wasserbade verkleistert, dann auf $70^{\circ} \mathrm{C}$. abgekühlt, mit $\check{5}$ cc Malzextract $(100 \mathrm{~g}$ Grünmalz $+500 c c$ Wasser) versetzt und einige Minuten zur Verflüssigung des Stärkemehls im Wasserbade bei $70^{\circ} \mathrm{C}$. erhalten. Um der Dunkelfärbung der Flüssigkeit vorzubeagen, wurde dieselbe mit $1 \%$ Weinsäure angesäuert. Die so vorbereitete Flüssigkeit unterwarf man dem Drucke von drei Atmosphären. Nach dem Erkalten wurden $5 \mathrm{cc}$ Malzextract hinzugefügt; sodann erwärmte man auf $70^{\circ} \mathrm{C}$, wobei nach circa 20 Minuten Stärkemehl vollständig gelöst wird. Ein Theil der abfiltrirten Flüssigkeit wurde mit Salzsäure von 1,125 specifischem Gewichte invertirt. In dieser Flüssigkeit wurde schliesslich mit Hülfe der Fehling'schen Kupferlösung Zucker und indirect Stärkemehl bestimmt. Man darf aber nicht vergessen, von der gefundenen Zuckermenge die den zugesetzten $10 c c$ Malzextraçt entsprechende Zahl abzuziehen.**)

Die nach den beiden Methoden ausgeführten Analysen haben sehr gut übereinstimmende Resultate ergeben. Die Versuche habe ich mit mehreren durch die Brauerei eingekauften Gersten ausgeführt. Zwei von diesen Analysen theile ich hier als Beleg mit:

\begin{tabular}{l|l|c|c|c|c|}
\hline & \multicolumn{2}{|c|}{$\begin{array}{c}\text { Sächsische Gerste } \\
\text { Märcker }\end{array}$} & $\begin{array}{c}\text { Oberländer Gerste } \\
\text { Asbóth }\end{array}$ & $\begin{array}{c}\text { nach } \\
\text { Märcker }\end{array}$ & $\begin{array}{c}\text { nach } \\
\text { A sbóth }\end{array}$ \\
\hline Wasser . . . . . & $13,92 \%$ & - & $14,15 \%$ & -
\end{tabular}

Die wasserfreie Substanz enthält:

\begin{tabular}{|c|c|c|c|c|}
\hline Fett & $1,63 \%$ & - & $1,05 \%$ & - \\
\hline Asche & $2,81 \pi$ & - & 2,43 & - \\
\hline Stärkemehl & 77,63 & $77,75 \%$ & 80,76 , & $80,94 \%$ \\
\hline
\end{tabular}

*) Chemiker-Zeitung 1888, Nr.42. Zeitschrift f. gesammt. Brauwesen 1889, Nr. 13, S. 266. S. 94 .

**) Genaue Beschreibung dieser Methode in Märcke r's Handbuch, IV. Aufl. 
Diese Versuche beweisen, dass die Methoden von Dr. A s b óth und von Märcker als gute und ubereinstimmende Resultate liefernde zu bezeichnen sind, während diejenige Methode, welche auf directer Inversion mit Säuren beruht, meiner Ansicht nach auf keinen Fall bei Gersten-Untersuchungen als zuverlässig betrachtet werden kann, denn es werden hier auch andere Körper, wie Cellulose und Pectinstoffe, als Stärkemehl in Rechnung gebracht. *)

Bei Zùckerbestimmungen darf man bei genauen Untersuchungen nur die Allihn'sche gewichtsanalytische Bestimmung oder die Soxhlet'sche maassanalytische Bestimmung anwenden, da die Reisch a u er'sche Methode nur annähernde Resultate liefert.

Dortmund, Laboratorium der Branerei $\gg$ Kronenburg «, im Febr. 1890.

Zur chemischen Untersuchung der Industriegase.

Von

\section{Dr. Otto Schmidt.}

Zur Probenahme von Feuerungsgasen bediene ich mich folgenden leicht zu construirenden Apparates, welcher den Vorzug hat, einmal in Gang gesetzt, eine grössere ununterbrochene Reihe von Rauchgasanalysen zu gestatten.

Figur 8 veranschaulicht imWesentlichen die Haupttheile des Apparates.

a ist ein mit Wasser gefüllter Säureballon, welcher mittelst eines doppelt durchbohrten Gummistopfens luftdicht verschlossen ist. $b^{\prime}$ ein bis auf den Boden des Ballons reichender Heber, der bei b" mittelst eines Quetschhahnes geschlossen werden kann. $\mathrm{c}$ ein auf beiden Seiten mit durchbohrten Gummistopfen geschlossener Glascylinder, der bei I mit der aus der Feuerungsanlage kommenden Leitung verbunden ist. i stellt einen zwischen beide Theile eingeschalteten und mit Glaswolle gefüllten Cylinder dar, welcher den Zweck hat, Staub und Russ zurückzuhalten. Mit $\mathrm{c}$ steht das T-Rohr $d$ durch den Gummischlauch $\mathrm{m}$ in Verbindung und ersteres durch das mit Hahn g versehene Rohr mit dem Ballon selbst.

Soll der Apparat benutzt werden, so öffnet man die Hähne $b^{\prime \prime}$ und $g$, schliesst e und setzt durch Ansaugen bei $n$ den Heber $b^{\prime}$ in Thätigkeit.

*) Arbeiten von Stumpf und Delbrück, Märcker, Morgen. 